\title{
The Flammability of Poly-xylyleneadipamide Fiber
}

\author{
By Kiyoshi Ishii, Tatsuo Takaya and Fumihide Fujimoto, Members, TMSJ \\ Takatsuki Research Center, Toyobo Co. Ltd., Takatsuki, Osaka
}

Based on the Journal of the Textile Machinery Society of Japan, Transactions, Vol. 26, No. 5, T 79-83 (1973)

\begin{abstract}
The fllammability of Poly-xylyleneadipamide (XDA-6) fiber was investigated by LOI (Limiting Oxygen Index) test, APEX test and $45^{\circ}$ Coil test. The flash point and the ignition behavior were also studied by using an electric furnance. LOI value of XDA-6 is a little higher than that of nylon 6 and PET. APEX test shows that XDA- 6 fabric is difficult to ignite and burn rapidly except very light weight fabric. It was shown by $45^{\circ}$ Coil test that XDA- 6 fabric is difficult to continue burning but nylon 6 and PET fabrics are easy to burn.

According to the experimental results of XDA-6 fibers, no ignition point was found below $650^{\circ} \mathrm{C}$.

The thermogravimetric behavior of several fibers was studied and discussed in relation to the flammability of these fibers. XDA-6, nylon and PET show two ranges of weight-decreasing temperature while the weight loss in first range of XDA-6 is small compared with the others. The amount of the residue at $600^{\circ} \mathrm{C}$ were, in order, $17.0 \%$ (XDA-6), $8.8 \%$ (nylon 66 ) $3.8 \%$ (PET) and $1.5 \%$ (nylon 6 ).
\end{abstract}

Key WordS: Fire Resistance, Thermal Properties, Polyamides

\section{Introduction}

The flammability behavior of textiles is known to depend on their thermal properties (thermal decomposition, shrinkage, melting, exothermic and endothermic reactions) and on geometric structure (weight, weight per unit area, porosity, surface and roughness) as well as atmospheric conditions (temperature, Oxygen supply). It is difficult for us to evaluate the flammability of textiles in all cases. However it might be possible to conclude the true flammability of fibers by discussing the relationship between several flammability data and several thermal properties in certain suitable conditions. Poly-xylylene-adipamide fiber (XDA-6) was found to be difficult to ingite and to have some interesting flammability behavior ${ }^{[1]}$. In this paper, the flammability behavior of XDA-6 is discussed compared with Nylon or PET fibers.

\section{Experimental}

\section{2-1 Samples}

Poly-xylylene-adipamide (Copolymer of Metha-xylylene-diamine 73 mole \% and Para-xylylene-diamine 27 mole \%) fiber, Nylon-6, Nylon-66, Polyethylene-terephthalate (PET) fiber.

\section{2-2 Methods for Evaluating Flammability}

Flammability of textiles depends on atmospheric condition as well as on their own properties. The oxygen index

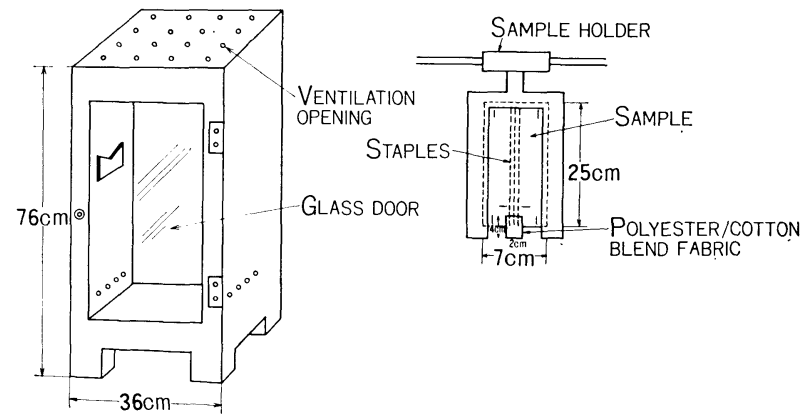

Fig. 1 Apparatus for APEX test

method was used to evaluate the inherent flammability of XDA-6. APEX test method and $45^{\circ}$ Coil method were used to evaluate the flammability of XDA- 6 to get rid of its dropping out by melting.

Testing methods and conditions are as follows;

A. Oxygen Index Method (ASTM D-2863-70 ${ }^{[2]}$ )

Limiting Oxygen Index (LOI) was measured. The method provides a measure of the minimal volume fraction of oxygen $\left[\mathrm{O}_{2} /\left(\mathrm{O}_{2} \pm \mathrm{N}_{2}\right) \times 100\right]$ in a slowly rising gaseous atmosphere capable of sustaining candle-like burning of the sample. LOI gives a reproducible measure of the inherent flammability characteristics of the fiber.

B. APEX Test Method ${ }^{[3]}$

Test specimen is laid up with one layer of fabric to be 


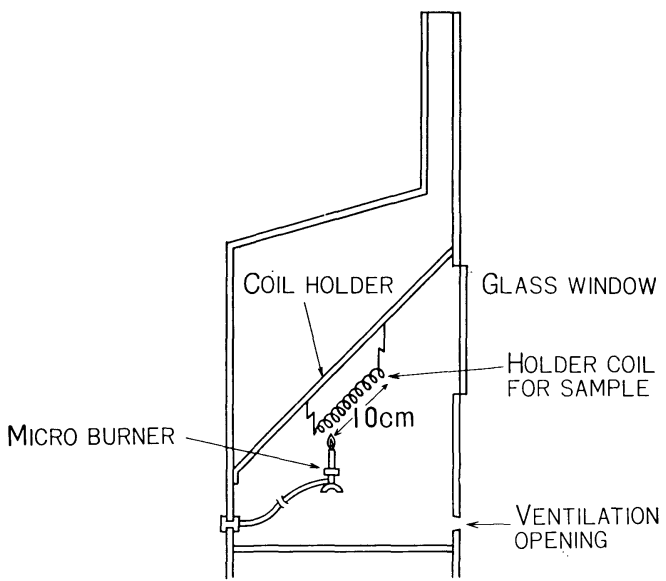

Fig. 2 Appatatus for $45^{\circ}$ coil method

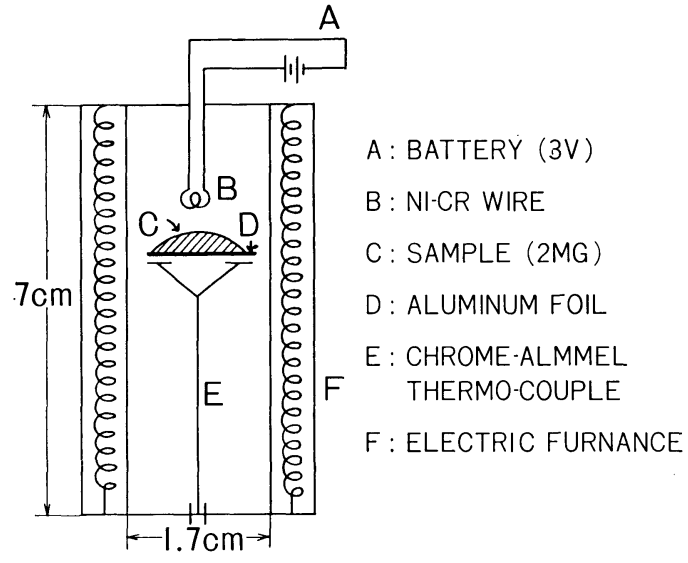

Fig. 3 Apparatus for measuring flash points tested, one layer of glass fabric and one layer of fabric to be tested. A strip of PET/Cotton (65/35) shirting $(4 \mathrm{~cm} \times 2 \mathrm{~cm})$ is hung below the bottom edge of the test specimen after it is fastened with staples. (Fig. 1).

Test specimen is mounted in the holder, which is suspended in the test cabinet of JIS-L-1079C. A match flame is applied to the center of the bottom edge of the PET/ Cotton fuse to ignite it. The burning characteristics are observed.

\section{C. $45^{\circ}$ Coil Method ${ }^{[4]}$}

The flammability test apparatus shown in Fig. 2 is used. Test specimen (10 cm wide, $1 \mathrm{~g}$ heavy) is made cylindrical and inserted into the coil holder, which is suspended in the cabinet at $45^{\circ}$ angle. The flame of the burner is placed in contact with the bottom edge of test specimen. If burning of the test specimen stops halfway, the flame of the burner is moved to the bottom of the residual specimen. Same operation is repeated until $9 \mathrm{~cm}$ of the specimen is melted or burned. The frequency the flame applied to a piece of the test specimen is measured.

\section{2-3 Method for Measuring Flash Points of Fibers}

A small electric furnance for DTA with a small heated $\mathrm{Ni}-\mathrm{Cr}$ wire as fire source is used. When the apparatus is heated at the rate of $30^{\circ} \mathrm{C} / \mathrm{min}$., the sample (cut fiber) is ignited at a certain temperature which is defined as flash point. The weight of the sample is $25 \mathrm{mg}$. The apparatus used is indicated in Fig. 3.

\section{2-4 Method for Measuring Ignition Points of Fibers}

The apparatus without $\mathrm{Ni}-\mathrm{Cr}$ wire in Fig. 3 is used. Although the ignition points of each fiber were not observed when the furnance was heated at the rate of $30^{\circ} \mathrm{C} /$ min., the ignition lag time between the sample insertion into the furnance and the ignition of the sample at a certain temperature could be measured.
2-5 Thermogravimetric Analysis (TG) Apparatus; Shimadzu-Micro-Thermogravimetric Analyser

Measuring condition

(1) Heating rate; $15^{\circ} \mathrm{C} / \mathrm{min}$

(2) Sample weight; $5.0 \mathrm{mg}$

(3) Sensitivity; $10 \mathrm{mg}$ full scale

\section{Results}

3-1 Evaluation of Flammability

The results of flammability tests on XDA-6, Nylon 6, Nylon 66 and PET by Oxygen Index Method, by APEX Test Method and by $45^{\circ}$ Coil Method are shown in Table 1.

Although LOI value of XDA-6 is only a little higher than those of Nylon 6 and PET, APEX Test shows that XDA-6 fabric is difficult to ignite and $45^{\circ}$ Coil test shows that XDA-6 has a fairly higher value compared with others. As XDA-6 fabric sometimes does not ignite and sometimes does ignite, the effect of the weight per unit area on flammability was studied.

Data shown in Table 2 indicate that XDA-6 in APEX test becomes difficult to ignite as weight per unit area is increased. On the other hand, Nylon 6 and PET do not show such behavior. In other test methods, there is no effect of weight per unit area on flammability.

3-2 Flash Points and Ignition Lag Time

Table 3 shows flash points, and Table 4 shows ignition lag time.

XDA-6 shows no flash point below $650^{\circ} \mathrm{C}$, but Nylon 6 , Nylon 66 and PET show flash points of about $450^{\circ} \mathrm{C}$.

\section{3-3 Thermogravimetric Analysis (TG)}

TG thermograms of several fibers are shown in Fig. 4. The major stages of weight losses and the remaining sample weights are summarized in Table 5. 
Table 1 Flammability Test Results

\begin{tabular}{l|c|l|c}
\hline Sample & L.O.I. & \multicolumn{1}{|c|}{ APEX Test } & $\begin{array}{c}45^{\circ} \text { Coil Test } \\
\text { (Frequency) }\end{array}$ \\
\hline XDA-6 & 23 & $\begin{array}{l}\text { Difficult to ignite but burns com- } \\
\text { pletely if it ignites }\end{array}$ & 4 \\
Nylon 6 & 20 & $\begin{array}{l}\text { Burns completely } \\
\text { Burns completely }\end{array}$ & 1 \\
PET & 22 & 1 \\
\hline
\end{tabular}

Table 2 Effect of Weight per Unit Area on Flammability

\begin{tabular}{c|l|c|c|c|c}
\hline Fiber & \multicolumn{1}{|c|}{ Structure } & Weight $\left(\mathrm{g} / \mathrm{m}^{2}\right)$ & APEX Test & $45^{\circ}$ Coil Test & L.O.I. \\
\hline \multirow{2}{*}{ XDA-6 } & Three stroke & 370 & $\bigcirc$ & $4-5$ & 23 \\
& Interlock fabric & 180 & $\triangle$ & 4 & 22 \\
& Rib fabric & 140 & $\triangle$ & 5 & 23 \\
& FAK tube knit* & 51 & $\times$ & 4 & 22 \\
\hline \multirow{2}{*}{ Nylon 6 } & Three stroke & 370 & $\times$ & $1-2$ & 20 \\
& Interlock fabric & 180 & $\times$ & 1 & 20 \\
& Rib fabric & 140 & $\times$ & 1 & 20 \\
& FAK tube knit* & 50 & $\times$ & $1-2$ & 20 \\
\hline \multirow{2}{*}{ PET } & Three stroke & 370 & $\times$ & 1 & 22 \\
& Interlock fabric & 180 & $\times$ & 1 & 22 \\
& Rib fabric & 140 & $\times$ & 1 & 22 \\
& FAK tube knit* & 50 & $\times$ & 21 \\
\hline
\end{tabular}

(Note) $\bigcirc:$ Not ignite $\triangle$ : Difficult to igni e but burns completely if it ignites $x$ : Burns completely *: FAK knitted farics made by Lawson-Hemphill Inc.

Table 3 Flash Points

\begin{tabular}{l|c}
\hline Fiber & Flash Points $\left({ }^{\circ} \mathrm{C}\right)$ \\
\hline XDA-6 & Not lower than $650^{\circ} \mathrm{C}$ \\
Nylon 6 & 459 \\
Nylon & 461 \\
PET & 448 \\
\hline
\end{tabular}

Table 4 Ignition Lag Time (sec)

\begin{tabular}{|c|c|c|c|c|c|c|c|}
\hline $\begin{array}{l}\text { Temperature }\left({ }^{\circ} \mathrm{C}\right) \\
\text { Sample }\end{array}$ & 450 & 500 & 525 & 550 & 575 & 600 & 650 \\
\hline XDA-6 & \multicolumn{3}{|c|}{ Not ignite } & 21.1 & 10.3 & 2.1 & 0.5 \\
\hline Nylon 6 & & & & 9.1 & 4.8 & 3.3 & 1.0 \\
\hline Nylon 66 & & & & 10.2 & 4.9 & 3.5 & 1.2 \\
\hline PET & & & & & 12.5 & 3.6 & 2.7 \\
\hline
\end{tabular}

Table 5 Summary of TG Data

\begin{tabular}{|c|c|c|c|c|c|}
\hline & \multicolumn{2}{|c|}{ First Stage } & \multicolumn{2}{|c|}{ Second Stage } & \multirow{2}{*}{$\begin{array}{l}\text { Wt. Remaining } \\
\left(\text { at } 600^{\circ} \mathrm{C}(\%)\right)\end{array}$} \\
\hline & Tem. $\left({ }^{\circ} \mathbf{C}\right)$ & Wt. loss $(\%)$ & Tem $\left({ }^{\circ} \mathrm{C}\right)$ & Wt. loss $(\%)$ & \\
\hline XDA-6 & $391-430$ & 510 & $545-637$ & 33.0 & 17.0 \\
\hline Nylon 6 & $428-483$ & 848 & $530-579$ & 8.5 & 1.5 \\
\hline Nylon 66 & $431-490$ & 795 & $545-640$ & 13.0 & 8.8 \\
\hline PET & $405-463$ & 810 & $535-578$ & 11.0 & 3.8 \\
\hline
\end{tabular}




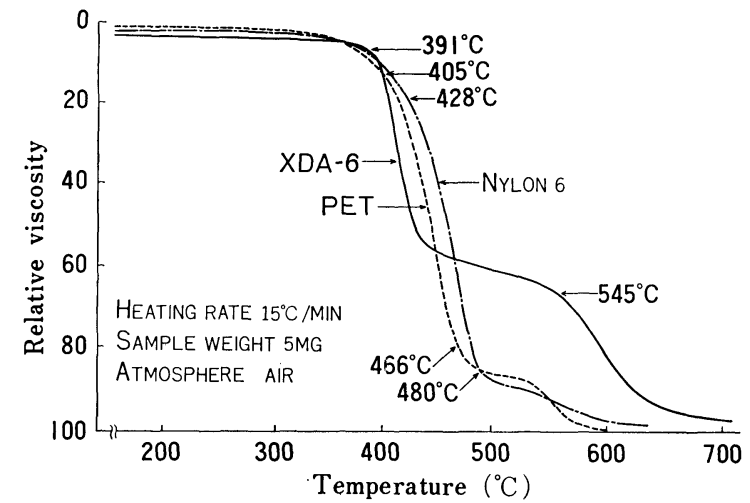

Fig. 4 TG thermogram

The weight loss of the first stage of XDA-6 is smaller than those of Nylon 6, Nylon 66 and PET, and the remaining weight of XDA- 6 at $600^{\circ} \mathrm{C}$ is larger than the others.

\section{Discussion}

XDA-6 has lower flammability than Nylon 6, Nylon 66 and PET. This property is affected by weight per unit area of the fabric. The lower flammability is remarkable fcr heavy weight fabric. When weight per unit area of XDAfabric is large, it is unable to continue to burn the fabric with a limited fire source. It is presumed that no ignition of heavy weighted XDA-fabric is due to the lower concentration of volatile flammable gases, because there is a large amount of residue. This behavior also corresponds to the result of flash point test. It is shown by TG that thermal degradation above about $450^{\circ} \mathrm{C}$ is mild, and that the remaining residue of char at $600^{\circ} \mathrm{C}$ is large. This thermal degradation behavior suggests the lower flammability of XDA-6.

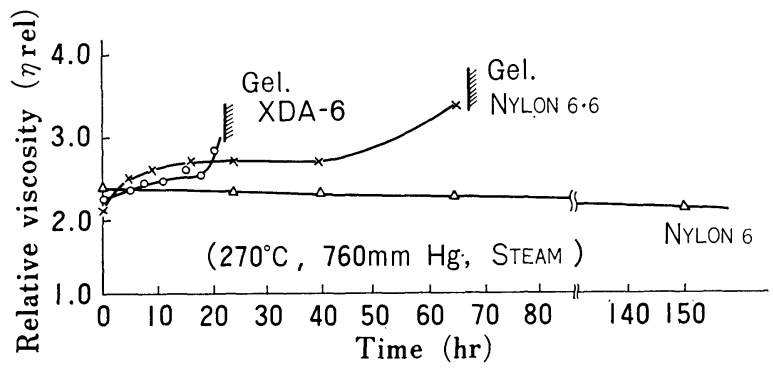

Kind and concentration of viscosity stabilizer used. XDA-6: Adipic dcid $0.49 \mathrm{~mol} \%$ Nylon 66: Adipic acid $0.34 \mathrm{molf} \%$ Nylon 6: None

Fig. 5 Viscosity change of polymers

It is known that XDA-6 polymer is easily gelled than Nylon 6 or Nylon $66^{[5]}$. This suggests that as XDA-6 is easier to crosslink between molecules than the others, it leaves a lot of char residue formed in flammability test.

Analysis of evolved gas has not yet been done.

\section{Acknowledgment}

Special thanks are due to Mr. K. Etoh and Mr. C. Tsukam to for helpful discussion about our work.

This work was presented at the 6th Conference Sponsored by Japanese textile and allied societies.

\section{Literature cited}

[1] K. Ishii, T. Sekiguchi and T. Takaya; Sen-i Gakkaishi, 28, 359 (1972)

[2] Modern Plastics, 47, No. 3, 124 (1970)

[3] A. S. Endler et al; Amer. Dyest. Rep., 56, 694 (1967)

[4] JIS-L-1091-1971

[5] C. Tsukamoto, H. Nagai, K. Etoh and F. Fujimoto; Kobunshi Kagaku 30, (1973) 